\title{
Forgery and counterfeiting documents: the expertise evidence: an exploratory research in oporto criminal
} \section{court}

\begin{abstract}
The current situation has been marked by the most diverse types of crime and, although little media, the fraud has been increasing the statistical data, much because of the social conjuncture that the country crosses. In this way, the courts are full of cases of falsification and counterfeiting of documents, an issue that only an expert in document analysis may be able to solve. An analysis of the data presented in the Annual Internal Security Reports ${ }^{1}$ - since 2007 - when Law No. 59/2007 of September 4 came into force, ${ }^{2}$ which amended the article that criminalizes this offense As we know it today, confirms that, although with minor variations, crimes against life in society, a category in which the illegal counterfeit or counterfeit document is framed, remain the third most frequent crimes. At the European level, Portugal remains at the top of the list for fraudulent documents $(n=67$ - data for 2012), followed by Italy and Spain. In 2009, with the introduction of a new foreign citizen's card, the measure that aimed to reduce the ease of forgery of identification documents did not break the trend that had been notorious, reaching $12.54 \%$ of cases of crimes against Life in society and, more recently, reaching $13.6 \%$. Given the current relevance of the phenomenon under study, this article seeks to make a brief allusion to the criminalization of the phenomenon in Portugal and, later, based on an exploratory study of 50 cases analyzed in the Ombudsmen of Porto, to make a characterization of the offenders and the type of the crime in question.
\end{abstract}

Keywords: counterfeiting, counterfeiting, expert evidence, manual writing, documents
Volume 4 Issue $6-2017$

\author{
Guerreiro A, ${ }^{1,2}$ Simas Santos $M^{2}$ \\ 'Department of Legal Medicine, Institute of Biomedical Sciences \\ Abel Salazar of the University of Porto, Portugal \\ ${ }^{2}$ Department of Criminology and Behavioural Sciences, \\ University Institute of Maia, Portugal
}

\begin{abstract}
Correspondence: Ana Guerreiro, Department of Legal, Medicine Institute of Biomedical Sciences Abel Salazar of the University of Porto, Rua de Jorge Viterbo Ferreira 228, 4050313, Porto, Portugal, Tel 35 I 913060 478,

Email ana.esteves.guerreiro@gmail.com
\end{abstract}

Received: October 3I, 2016 | Published: May II, 2017

\section{Introduction}

The crime of Falsification or Document Counterfeiting is a highly complex crime. This is due to the various legal aspects that it presents. At the base of this crime are also the forensic experts who urge as fundamental for the good prosecution of Criminal Law and Criminal Procedural Law. The crime of Falsification or Counterfeit Document, as its name indicates, typifies as illegality any modification of a document that may influence the legal traffic. This crime is found in Article 256 of the Portuguese Criminal Code ${ }^{1}$ inserted in Chapter II - "Of crimes of falsification" - of Title IV - "Crimes against life in society". The formulation of this offense, as we know it today, was introduced by the 1995 reform, which was later amended by Act No. 59/2007 of 4 September. $^{2}$ By document, and according to the designation that Article 255 of the Criminal $\mathrm{Code}^{3}$ presents to us, a statement embodied in the most diverse forms and that is suitable to prove a fact - probative function - and that can take in three forms: Constitute, modify or terminate a certain legal relationship. If the legal diploma clearly expresses the probative function that the document has, and there is no such characteristic, the writing is no longer considered a document with legal effects. The crime of Counterfeiting and Counterfeiting of Documents in Portugal punishes, therefore, the total counterfeiting of a document, the total or partial alteration of the contents of the document, the abuse of the signature, the fraudulent use of forged documents and the sale / To another (Article 256 (1)).

Among the analysis of this legal type, the first doubt that may arise is that the legal good is that criminalization protects: public faith or security in legal traffic. It is important, at the outset, to clarify that in the first instance it is the society that will be most affected by the consequences of this illicit since it is she who relies on the documents. Even so, what is really intended to be protected is the possibility that the falsification may call into question the security in the use of the document as a means of proof, hence that the legal asset harmed is security in legal traffic. As for the classification of crime of danger or crime of harm, we are facing a crime of damage when there is an injury of the legal good, while if we place the legal good in a situation that can easily cause damage but is not consummated, the we classify only as a crime of danger. In the crime of Forgery or Document Counterfeiting, the production of a modification in the document is in itself a crime of danger because, although there is no loss, there is a possibility that it may occur with the introduction of the Document in jurisdictional ways, damaging legal values protected by law. We are, therefore, facing a crime of danger. As far as the subjective type is concerned, the crime of falsification of documents does not admit, during its legal precept, the form of negligence, defining very clearly that the subjection of a certain suspect to this behavior is of a willful nature, when it refers in its. ${ }^{4}$ In this context, the term "intention to cause harm" or "obtain... illegitimate benefit". The penalty awarded to the offender is based on two different modalities: a prison sentence of up to three years or a fine. However, the penalty may be aggravated if the falsification is committed by an official (articles 256, no. 4 and $257 \mathrm{CP}$ ) or depending on the document in question (256, no. 3 PC). When a document is modified or altered, an expert may be called upon to carry out documentary examinations for a variety of reasons: either for the analysis of the writing that is affixed to the document, for the detection of writing marks, for the analysis of Obliterations or additions of the content, comparison of inks and paper and relative dating of documents. ${ }^{5}$ Thus, forensic analysis can have two types: 
the analysis of manual writing and the analysis of the document as a whole. Manual writing skills are a scientific analysis performed by forensic specialists who seek to find out if a writing is true and, if it is not, who is the author. ${ }^{6}$ This investigation of scientific criteria is based on a comparative method $^{7}$ in which the expert's objective is to study the details that are part of the original document and compare them with the suspicious document to determine their agreement or lack thereof. ${ }^{8}$ On the other hand, document analysis consists of an analysis of the document as a physical object that will serve as a means of identification and legitimation and which may allow to identify erasures, additions and obliterations, date the age of the document. ${ }^{5,9}$

\section{Materials and methods}

For the development of the study, and in particular for the characterization of the victims and defendants involved in the criminal processes of falsification and counterfeiting of documents of the Porto district, 50 cases were analyzed. The analyzed data were initially related to the sociodemographic characteristics of the subjects, such as age, sex, marital status, residence, naturalness, nationality, literacy; And, at a later stage, on the characteristics of the criminal proceedings and their respective expertise, such as the number of expert witnesses requested by the courts, the time elapsed from the request to the delivery of the expert report, the penalty applied and the type of documents that were the subject of expert analysis. The study took place in Porto's Criminal Courts, after a 3-month probationary period with access to and analysis of the lawsuits over the wrongdoing in question. The sample was collected randomly, with no tendency to choose one process over another.

For the procedural analysis a data collection grid created for this purpose was used and it was divided into four main sections:

i. Factors related to the offended,

ii. Sociodemographic characteristics of the offender,

iii. Factors related to crime, and

iv. Skills to Documents or Manual Writing.

The first section sought to classify the offended type by making a clear distinction between an individual or a legal person and, on the other hand, in case of being an individual, to characterize the offended partner demographically. The second section was designed to characterize the offender and, in addition to collecting the sociodemographic characteristics, information was also withdrawn from his criminal history, the purpose of which was to determine whether or not the offender was a repeat offender. Another section of analysis refers to the factors related to the crime in particular, namely the penalty applied to the defendant. Finally, it was also intended to gather information on the expertise carried out in order to understand what kind of expertise was requested and the time elapsed from its request to the submission of the final report. All data were entered and statistically analyzed using the IBM Software Statistical Package for the Social Sciences (SPSS) for Windows, version 22.0.

\section{Results}

\section{Injured}

Of the 50 cases analyzed, 53 were injured. The injured parties were divided into Single Person and Collective Person as the forgery and counterfeiting of documents would harm an individual person without any link to a commercial entity or if the injured person directed a commercial entity. It is concluded that the study analyzed 29 individuals and 24 legal persons, representing a percentage of $54.7 \%$ and $45.3 \%$, respectively.

Since the analysis of sociodemographic characteristics is only possible in natural persons, the study will not focus on legal persons. Of the total number of natural persons $(n=29), 11(37.9 \%)$ were female and $18(62.1 \%)$ were male. With respect to age, only 28 cases were considered since it was not possible to obtain the age of one of the injured. Thus, most of the victims are between 30 and 40 years of age, with a percentage of $35.7 \%$, followed by a percentage of $14.3 \%$ for individuals between the ages of 40 and 50 and between 50 and The 60 years. However, it is against people between the ages of 70 and 80 that the crime of Document Counterfeiting or Counterfeiting is less committed, with a total of $3.6 \%$ of cases. Concerning marital status, the victims are predominantly married $(\mathrm{n}=11,37.9 \%)$, with 8 $(27.6 \%)$ divorced, with the same percentage for single people and 2 $(6.9 \%)$ widowers.

Another of the studied variables was the schooling of the injured. Of the 29 singularly injured individuals, it was only possible to extract this information from 8 cases. Schooling was divided according to the categorization implemented in Portugal. Of the 8 valid cases, 2 $(25 \%)$ of them attended only the 1 st cycle and the same number was verified in relation to secondary education. The second cycle was the level of schooling that showed the existence of a greater number of cases (3) reaching, therefore, a percentage value of $37.5 \%$. As for the 3 rd cycle, only one person attended (12.5\%). As regards the profession of natural persons $(n=29)$, the data relate to 28 persons, since it was not possible to obtain the professional status of a case. The professions were grouped according to the list of professions regulated by the Institute of Employment and Professional Training (IEFP). Most of the victims are retired (17.9\%) and representatives of the legislative and executive bodies, directors, directors and executive managers $(17.9 \%)$. There is a considerable percentage of unskilled workers (14.3\%) and specialists in scientific and intellectual activities $(10.7 \%)$. Regarding nationality, the analysis of the cases allowed to infer that the nationality of all the injured as individuals is Portuguese.

\section{Suspects}

Of the 50 analyzed cases, a higher number of suspects was observed in relation to the number of victims $(\mathrm{n}=59)$. Of the 59 suspects, 42 are males and 17 are females, representing percentage values of $71.2 \%$ and $28.8 \%$, respectively. For the analysis of age, 56 cases were considered due to the impossibility of collecting this variable in 3 of the individuals. The highest incidence of suspects is between 30 and 40 years old with a percentage of $39.3 \%$, followed by a $30.4 \%$ percentage for suspected persons between the ages of 20 and 30 . Regarding the Civil Status, the sample consisted of only 57 cases. The majority of the suspects were single $(\mathrm{n}=24-42.1 \%)$, with a very close married $(\mathrm{n}=22-38.6 \%), 9$ divorced suspects $(15.8 \%), 1$ (1, $8 \%)$ widowed and 1 (1.8\%) in union. As for schooling, the criterion of division was the same as for the injured, with only 30 of the 59 cases analyzed in this case. Most of this sample has reasonable levels of education in the second cycle $(\mathrm{n}=9,30 \%)$ and in secondary education $(\mathrm{n}=11,36.7 \%)$. Only 4 suspects $(13.3 \%)$ studied only the 1 st cycle against $6(20 \%)$ of the 3 rd cycle. As for the profession, and following the same framework as the injured, it was only possible to analyze 45 cases. Most of the suspects are unemployed (20\%) and personal, security and safety service workers and sellers (20\%). Skilled workers 
in industry, construction and artifices (15.6\%) and representatives of the legislative and executive bodies, directors, directors and executive managers $(13.3 \%)$ also occupy a considerable occupational position of the suspects. The nationality of suspects varies. In the 59 suspects, $50(84.7 \%)$ are Portuguese and $4(6.8 \%)$ are Ukrainians. In addition to these nationalities, there are equal numbers $(n=1,1.7 \%)$ for Angolan, Brazilian, Nepalese and Nigerian nationalities.

\section{Processes}

Of the 50 analyzed cases, the most analyzed documents were checks $(30 \%)$, promissory notes $(14 \%)$, identification documents citizen / BI card and passport (12\%) - driving licenses ), Coupons ( $8 \%$ ), contracts $(6 \%)$, registration plates $(4 \%)$, minutes $(2 \%)$ and certificates $(2 \%)$. Regarding the suspect and his criminal record, in $67.8 \%$ of the cases, the individuals did not have a criminal record to counter with $32.2 \%$ who had committed crimes at some point. Among the most committed crimes are Document Falsification or Counterfeiting, Plain Burglary, Simple Theft, Narcotics Trafficking, Driving without Legal Entitlement, Domestic Violence, Disobedience, Drunk Driving, Abuse of Trust and the simple Physical Integrity Offense.

As regards the charge for the crime in question, the different suspects were accused in $74 \%$ of the cases solely and exclusively for the crime of Falsification or Document Counterfeiting. Cumulatively for the crimes of Burla and Falsification or Counterfeiting of Document were accused $26 \%$ of the processes. Regarding the measure of punishment, the analysis showed that most of the suspects were sentenced to a fine $(49.2 \%)$ and that cases still awaiting trial are close to this figure $(32.1 \%)$. A small percentage of the suspects were sentenced to imprisonment (5.1\%), and there were also very low numbers of suspended prison sentences $(3.3 \%) .8 .5 \%$ of the suspected suspects were acquitted and $1.7 \%$ of the procedures prescribed. In relation to the time interval from the date of fact until the date of the reading of the sentence, of the 50 cases, in only 35 of the cases was the end of the criminal process. Thus, cases that took up to 5 years to be judged had a percentage of $34.3 \%$, while those with a duration between 5 and 10 years had a percentage of $65.7 \%$. Of the 50 cases, it was only possible to extract data from 19 expert reports. Of these 19 , although the request was sent, it was not possible to perform 4, since the sample was not of sufficient quality. Thus, of the remaining $15,33.3 \%$ took up to 5 months from the request to the arrival of the expert report; $13.3 \%$ took between 5 and 10 months; Between 10 and 15 months, there was a total of $33.3 \%$ of the skills; From 20 to 25 months, the period that elapses between the request of the expert examination until the report was delivered had a percentage value of $13.3 \%$ and in only $6.7 \%$ of the cases the time interval was between 30 and 35 months.

\section{Discussion of results}

The purpose of the study was to characterize the profile of the victims and suspects involved in the crime in question. The results were analyzed in a characterization section, in which the risk profile of being a victim of this type of illicit was described and the risk profile of becoming a forger. There were 53 injured individuals divided into individuals and legal persons. In the present investigation we wanted to clarify the predominance of the different variables in relation to natural persons. As for sex, the majority of the victims are men, representing a value of $62.1 \%$. Also the Directorate General of Justice Policy (DGPJ) reveals data in which the victims of crimes against life in society do not present great differences in relation to sex. Nevertheless, the male subjects are predominant, since this study also corroborates. The $30-40$ age groups had the highest prevalence rate $(35.7 \%)$, with some incidence in the following groups. Although the scale of measurement is different, the DGPJ assigns more than 4000 thousand victims above the age of 24 to crimes against life in society, numbers that are discrepant in relation to inferior ages. With regard to the report of the Portuguese Victim Support Association of 2013 , the age range most likely to be a victim of crime is between 25 and 54, with a special focus on the ages of 35-44. Married men are the largest group with a propensity to be victimized (37.9\%) and also have low literacy rates, which are mainly related to the second cycle of schooling $(37.5 \%)$. Concerning the profession of the injured, the investigation was faced with equal percentage values (17.9\%) for retirees and representatives of the legislative and executive bodies, managers, directors and executive managers.

All the victims are of Portuguese nationality, being mostly natural of the city of Porto $(58.6 \%)$ and resident in the same city (62.1\%). Regarding the suspects, of the 59 analyzed, it was possible to conclude that they are mostly males (72.1\%) with an age between 20 and 40 years old who, according to the data analyzed, presented percentage values of $30.4 \%$. For ages between $20-30$ years and $39.3 \%$ between $30-40$ years. The theories that relate crime to gender attribute to men a greater predisposition to crime, in addition to stating that they are also more aggressive. ${ }^{10}$ As for marital status, they are mostly single (42.1\%) - although there is also a high percentage of marriages (38.6\%), with high levels of education, mainly at secondary level (36.7\%). The same amount of unemployed (20\%) and individuals working in the personal, security and security services and sellers (20\%) represent the professional occupation of the suspects. The high incidence of the unemployed involved in the illicit can be explained through the sociological theories of crime that defend that the social conditions in which the suspect is inserted influence their predisposition for criminal behavior. ${ }^{11}$ Risk factor, such as extreme poverty and inequality of opportunity. ${ }^{12}$ A large part does not present criminal records (67.8\%), incurring illicit as an isolated act. In this sense and considering the primordial age range in which this type of crime is committed (20-40 years), the criminological studies done on the recidivism confirm the existence of criminal antecedents since they are the individuals that at young age have behaviors Disruptive, which are more likely to have delinquent careers. ${ }^{13}$ An increasing number of transgressors are of Portuguese nationality $(84.7 \%)$ although there are individuals of other nationalities. The Immigration, Borders and Asylum Report of the Aliens and Borders Service corroborates these data, noting that most of the holders of fraudulent documents are of African nationality. ${ }^{14}$ International studies differentiate two types of forger: the opportunist and the predator. Considering the high number of individuals without criminal records that the present investigation encompassed, the most appropriate is to have the opportunist as a basis for comparison. This study presents the suspect as being middle-aged, male and married, traits that meet the profile described above.(Table 1). ${ }^{15}$

Considering also the analysis of the process and the expertise requested, the investigation indicates that the documents most sensitive to the forgery are the checks $(30 \%)$, much due to the economic benefit that may come from them, and that the most habitual condemnation is the penalty of fine $(49.2 \%)$, established in accordance with article 47 of the Criminal Code, being, as a rule, the minimum limit of 10 days and the maximum of 360 in variable rates between 5 and $500 €$. With regard to procedural speed, proceedings tend to take up to 5 years for a final decision to be handed down (65.7\%), despite the defendants or 
the injured parties appealing to higher courts. This period of time may easily be justified for the period from the request of the documentary expertise until the expert report which, according to the investigation, may take up to 5 months $(33.3 \%)$ or in cases where the volume of Laboratory work is high, up to 15 months (48.6\%) (Tables $2 \& 3$ ).

Table I General characteristics of the victims and offenders of the crime of falsification and counterfeiting of documents

\begin{tabular}{lll}
\hline Variables & Offended & Offender \\
\hline Sex & Male & Male \\
Age & $30-40$ & $20-40$ \\
Civil status & Married & Not married \\
Educational & 2nd cycle primary & High school \\
Qualifications & education & Unemployed; \\
Profession & $\begin{array}{l}\text { Retired; Representatives } \\
\text { of }\end{array}$ & Personal, \\
& the Legislative & Protective and \\
& Power and of & Security \\
& Executive Bodies, Officers, & Services and \\
& Directors and Executive Managers \\
& Portuguese & Portuguese \\
& &
\end{tabular}

Table 2 Sample procedural characteristics

\begin{tabular}{ll}
\hline \multicolumn{2}{l}{ Processual characterization of the Sample } \\
\hline Type of most falsified documents & Cheques (30\%) \\
Criminal Offender Background & No history $(67.8 \%)$ \\
Attributed penalty & Fine Penalty $(49.2 \%)$ \\
Time elapsed until process completion & 5 years $(65.7 \%)$ \\
\hline
\end{tabular}

Table 3 Characteristics of the expert analysis

Expert analysis
$\begin{aligned} & \text { Time elapsed from the request for } \\
& \text { expertise }\end{aligned}$
\begin{tabular}{ll} 
to the submission of the report & Up to 5 months $(33.3 \%)$ \\
\hline
\end{tabular}

\section{Conclusion}

As has been seen throughout the article, most counterfeits involve documents for the identification and legitimation of rights and property, documents which are often associated with other types of illicit acts, corroborating the idea that the crime postulated by the Article 256 of the Criminal Code is not an isolated crime. ${ }^{16}$ Examples of crimes related to Document Falsification or Counterfeiting are Drug Trafficking, Trafficking in Persons, Illegal Immigration Assistance, Terrorism, Corruption, and Homicide. The importance of the cooperation of the various forensic sciences also concerns this purpose of related crimes, inasmuch as medical and legal examinations combined with forensic expertise, such as documentary evidence, will result in a greater and more effective criminal justice And, therefore, social. From the present work we intend to present a study that aimed to characterize the profile of the offender and the victim in the crime of Falsification or Counterfeit Document in Portugal and the expert evidence that underlies it. While the objective was achieved, it was in the best interest to extend the study in order to gain a better understanding of the characteristics of the suspect and the injured, as well as perceive the weaknesses of the forensic laboratories themselves in order to intervene in the improvement and speed of services. In this follow-up, future studies may also focus on the falsification of digital documents, a topic that is very little developed today but of great relevance since we are part of a society controlled by technology.

\section{Acknowledgments}

None.

\section{Conflicts of interest}

None.

\section{References}

1. Annual Report on Homeland Security. Obtained from Government of Portugal, RASI, Portugal. 2016.

2. Lei N. from September 4th. 2007.

3. Código P. Obtained from. 1995.

4. Leal Henriques M, Santos SM. Annotated Penal Code. King of Books, Portugal. 2000;1-1640.

5. Violante J, Cunha N. Contested Document Analysis: Brief Approach to Document Counterfeiting. In: Pinheiro MF. Editors. Forensic Science at the Service of Justice. Potugal. 2013;371-392.

6. Jackson AR, Jackson JM. Forensic Science. 3rd edn. Pearson, UK. 2011.

7. Branco MJ. Escrita Manual: Princípios Básicos do Exame Pericial. In: Pereira MF (Eds), Ciências Forenses ao serviço da Justiça, Pactor, Portugal. 2013;343-369.

8. Hilton O. Scientific Examination of Questioned Documents. Rev ed, Elsevier, USA. 1993;1-424.

9. Herley C, Vora P, Yang S. Detection and Deterrence of Counterfeiting of Valuable Documents. Institute of Electrical and Electronics Engineers, Inc., USA. 2004;1-4.

10. Denno DW. Gender, Crime, and Criminal Law Defenses. Journal of Criminal Law and Criminology. 1994;85(1):80-180.

11. Justice MO. Theories of the Causes of Crime. Obtido de Ministry of Justice, New Zealand. 2009;1-9.

12. Martins MJ. Aggressive behavior in adolescence: Risk and protective factors. Psychological Analysis. 2005;2(23):129-135.

13. Loeber R, Farrington D, Petechuck D. Child Delinquency: Early Intervention and Prevention. Child Delinquency Bulletin Series, US Department of Justice, USA. 2003;1-20.

14. Dias P, Machado R, Estrela J, et al. Relatório de Imigração, Fronteiras e Asilo. Serviço de Estrangeiros e Fronteiras, Portugal. 2012;1-77.

15. Global profiles of the fraudster. Obtido de KPMG - cutting through complexity. KPMG, Portugal. 2011.

16. Artur P. As Perícias na Polícia Judiciária. Polícia Judiciária, Portugal. 2004;1-50. 